\title{
Reviews on books, internet and scientific media
}

Published online: 24 March 2009

(C) Springer-Verlag 2009

\section{W. Mike Edmunds and Paul Shand (eds): Natural groundwater quality \\ 2008 | Blackwell Publishing | 488 pp | 167 figs | USD \\ $157.99|£ 75.00| € 101.30$ | ISBN: 978-1-4051-5675-2}

\section{Reviewed by Gheorghe Ponta}

The book, Natural Groundwater Quality, brings together the research of European scientists who have conducted detailed studies of water quality in Europe, with recommendations regarding aquifer evaluation, quality indicators, and drinking water standards. The book has 21 chapters covering inorganic and organic quality of European aquifers, timescales and tracers, baseline trends and monitoring. Each chapter is well-illustrated with black-and-white figures (maps, cross sections, diagrams).

The European Water Framework Directive (WFD) forms the primary legislation for the protection of the European aquatic environment. The Groundwater Directive (GD) introduced in late 2006 has been incorporated to supplement the WFD and deal with specific questions of groundwater quality.

The aim of this book, as W.M. Edmunds and P. Shand state in the preface, "is to provide a key reference text on natural water quality of aquifers through a series of thematic chapters, together with chapters on representative groundwater systems in Europe which illustrate well the main processes and evolution of water quality".

G. Ponta $(\bowtie)$

P.E. LaMoreaux and Associates, Inc, 1009A 23rd Avenue, Tuscaloosa, AL 35401, USA

e-mail: gponta@pela.com
The criteria for defining natural background water quality are developed to provide, as far as possible, a standardized Europe-wide approach (geochemical approach, baseline criteria, geochemical modeling, isotope, noble gas tracers).

The baseline was defined in this book as the range of concentrations of a given element, isotope or chemical compound in solution, derived entirely from natural, geologic, biologic, or atmospheric sources, under conditions not perturbed by anthropogenic activity.

Trends in natural baseline have been established for aquifers in most countries over a period of decades. Two types of trends are observed: natural trends resulting from time-dependent geochemical reactions which are manifested mainly at the spatial scale, and non-baseline trends such as marine intrusion which are induced by pumping.

Twenty-five reference aquifers from 12 European countries (UK, Denmark, Poland, Estonia, Belgium, France, Spain, Portugal, and Switzerland, together with the Czech Republic, Bulgaria, and Malta) form the basis of the book. For each aquifer, median and upper baseline values are determined for over 50 inorganic parameters.

The public perceptions of water quality were established among end users from all partner countries. Results indicate acceptance of the value of maintaining pure, natural groundwater and support of the principle that the protection of supplies should be a top regulatory and managerial objective. A strategy for baseline monitoring has been produced to define the natural background status of groundwater bodies and aquifer systems. It is hoped that the adoption of the scientific principles developed here and more integration of science into policy will lead to more sustainable management of our precious aquifers. The book concludes with a synthesis about baseline concentrations and definitions of background levels. 